\title{
A Comparative Study on the Flexural Behaviour of One-Way Concrete Slabs Reinforced with GFRP Reinforcements and Conventional Reinforcements when Subjected to Monotonic and Repeated Loading
}

\author{
R. Sivagamasundari* and G. Kumaran ${ }^{\dagger}$
}

\author{
${ }^{*}$ Senior Lecturer and ${ }^{\dagger}$ Professor of Structural Engineering, Dept of Structural Engineering, Annamalai University, \\ Annamalai Nagar-608 002, India
}

\begin{abstract}
Over the last couple of decades, the interest in using advanced high performance materials in the construction industry has been shooting up and developing to reduce the overall life-cycle costs of structures. Accordingly, many researches have been carried out to invent new materials which possess the properties comparatively more advantageous than conventional steel reinforcements. Fibre Reinforced Polymer (FRP) reinforcements are considered as new, high tech and ideal materials optimistically used in many countries in the construction field especially in the construction of bridge deck slabs. So many researches have been done to assess the mechanical properties of FRP reinforcements, flexural and shear behaviours of FRP reinforced structural elements under static or monotonic loading. But only limited works have been brought out on the fatigue performance of FRP reinforced structural elements. This paper presents the flexural behaviour of one-way slabs reinforced with Glass Fibre Reinforced Polymer (GFRP) reinforcements (special type of FRP reinforcements) under monotonic loading and two different schemes of repeated loading. A total number of twenty one GFRP reinforced concrete one- way slabs were constructed, out of which seven were tested under monotonic loading, seven were tested under constant amplitude repeated loading and the remaining seven slabs were tested under variable amplitude repeated loading conditions. The behaviour of GFRP reinforced slabs were compared with that of steel reinforced slabs. It has been found that the ultimate load carrying capacities and fatigue performance of GFRP slabs were greater than that of steel slabs. Also there exists a good agreement between the theoretical and experimental results.
\end{abstract}

Key Words: Glass fibre reinforced polymer reinforcements, Concrete one way slabs, Monotonic loading, Constant amplitude repeated loading, Variable amplitude repeated loading.

\section{INTRODUCTION}

The corrosion phenomenon of concrete structures reinforced with steel has motivated the researchers to investigate alternative solutions to overcome this problem. Though many solutions have come into action, the use of non metallic materials became one of the promising alternative solutions. Being non corrosive in nature and thermally non conductive the FRP composites have been suggested by researchers as suitable reinforcement for concrete structures instead of steel. FRP composites are very easy to shape and form, this is always not possible with other high strength materials. FRP composites are anisotropic and possess good strength along the fibre length, but reduced strength across the fibre axis. Several codes and design guidelines like ACI code and CAN/CSA code $[1,2]$ etc. allow the use of GFRP bars as main reinforcement for concrete structures such as bridge decks, floor slabs and wall type structures (abutments, stems and wing walls). In these members, flexural strength is provided by the longitudinal reinforcement and shear strength is provided by the concrete only.

Tensile properties of FRP reinforcing bars range from 450 to $3500 \mathrm{~N} / \mathrm{mm}^{2}$ in terms of tensile strengths, 38000 to $300000 \mathrm{~N} / \mathrm{mm}^{2}$ in terms of Young's modulus and 0.8 to 4.0 $\%$ in terms of failure strains [3]. Tensile strength is also influenced by the diameter of the reinforcement (similar

*Address correspondence to this author at the Senior Lecturer, Dept of Structural Engineering, Annamalai University, Annamalai Nagar - 608 002, India; E-mail: siva_1667@yahoo.com effects do not exist in the case of conventional steel reinforcement). Due to shear lag effect fibres located near the centre axis of the bar cross section are not subjected to as much stress as those fibres that are near the outer surface of the bar [4]. This phenomenon results in reduced strength and reduced efficiency of larger diameter bars [5]. The most important characteristic of non-metallic reinforcement is its linear elastic behaviour up to failure without any plasticity and considerable release of elastic energy. As FRP reinforcements exhibit linear characteristics up to ultimate load, without yielding, it is appropriate to use only elastic methods of analysis. For design purposes it should be assumed that no redistribution of the elastic bending moments and shear forces would take place. FRP reinforcements have much potential as longitudinal reinforcement in slab type concrete structures and stressed primarily in bending. Slabs are always susceptible to repeated loadings. Consequently, fatigue performance is an important limit state that must be taken into account by the designers. Kae-Hwan Kwak [6] et al. (2001) studied the damage mechanism due to shear fatigue behavior of high strength reinforced concrete beams under repeated loading. The relationship between number of cycles and deflection, crack growth and modes of failure with the increase of number of cycles, fatigue strength and S-N curve were observed through fatigue test. Amr EI Ragby et al. [7] (2007) investigated that the fatigue performance of five full size two way deck slabs reinforced with GFRP reinforcements under concentrated cyclic loading in two different schemes like constant and variable amplitude of fatigue loading. Among the various non-metallic reinforce- 
ments that are available in the construction field, GFRP reinforcements are less expensive than the carbon FRP, aramid FRP etc.and hence it is more attractive to the infrastructure application and construction industry.

The use of GFRP reinforcements, in lieu of conventional steel reinforcements requires better understanding under different loading and performance conditions. Considerable researches have been carried out mainly on FRP reinforced concrete specimens under monotonically increasing load. Only limited research works have been carried out on FRP reinforced concrete specimens under pulsating or repeated loading conditions. This paper presents the flexural behaviour of one-way slabs reinforced with GFRP and conventional reinforcements under monotonic loading and repeated loading of two different schemes (constant and variable amplitude of fatigue loading).The experiments have been carried out on twenty one slabs, out of which eighteen slabs were reinforced with GFRP reinforcements (three grooved GFRP reinforced slabs and the remaining sand coated GFRP reinforced slabs) and three slabs were reinforced with steel (Fe 415) reinforcements. Sand coated slabs were constructed with three different reinforcement ratios $(0.65 \%, 0.82 \% \& 1.15 \%)$, two different thicknesses of the slab $(100 \mathrm{~mm}$ and $120 \mathrm{~mm})$ and two different grades of concrete $\left(\mathrm{M}_{20} \& \mathrm{M}_{30} \mathrm{~N} / \mathrm{mm}^{2}\right)$. Grooved and steel reinforced slabs were constructed with a reinforcement ratio $0.65 \%$, thickness of the slab $100 \mathrm{~mm}$ and grade of concrete $\mathbf{M}_{20}$ $\mathrm{N} / \mathrm{mm}^{2}$.

\section{Behaviour of Plain Concrete, Steel and FRP Reinforce- ment when Subjected to Fatigue Loading}

Fatigue is a permanent internal structural (micro cracking) change in a material subjected to fluctuating stresses or strains, if the stress level exceeds a certain limit. Plain concrete when subjected to fatigue loading, exhibits steeply increasing strains at the beginning of fatigue loading within short duration, and then followed by longer period of steady or slightly increasing strains with early age micro cracks in the cement matrix at the interface with the aggregates. The modulus of elasticity decreases significantly during the fatigue loading due to crack formation at the microscopic level. The fatigue life of steel reinforcement is categorized into three phases such as a crack initiation phase, a steady crack propagation phase and brittle fracture. Surface characteristics of steel reinforcements like deformation and roughness also influence the fatigue strength. As FRP composites are inherently heterogeneous, the damage mechanisms under fatigue loading are matrix cracking, fibre matrix debonding, void growth and fibre breakage. Concrete is believed to affect the fatigue behaviour of FRP reinforcements in the harsh environment and due to friction between the rods and concrete, which results in abrasion of the rod surface $[8,9]$.

\section{MATERIALS AND METHODOLOGY}

\section{Details of the Experimental Program}

The experimental program consisted of twenty one one-way slabs of length $2400 \mathrm{~mm}$ and $600 \mathrm{~mm}$ width. A bottom concrete cover of $20 \mathrm{~mm}$ was used for all the slabs. The slab specimens were cast using normal weight concrete of grade 20Mpa and 30Mpa.After casting, the specimens were allowed to cure for about 28 days which helps the concrete to stabilize its own properties like compressive strength and modulus of elasticity. Table 1 presents the mix proportions and properties of ingredients of concrete. Table 2 presents the mechanical properties of the materials.

Table 1. Properties of Concrete

\begin{tabular}{|c|c|c|}
\hline Material & $\mathbf{M}_{\mathbf{2 0}}$ Grade of Concrete & $\mathbf{M}_{\mathbf{3 0}}$ Grade of Concrete \\
\hline \hline Cement & $62 \mathrm{~kg}$ & $77 \mathrm{~kg}$ \\
\hline Fine aggregate & $80 \mathrm{~kg}$ & $84.7 \mathrm{~kg}$ \\
\hline Coarse aggregate & $183 \mathrm{~kg}$ & $204.82 \mathrm{~kg}$ \\
\hline water & 28 litres & 31 litres \\
\hline
\end{tabular}

\section{Experimental Set up for Different Loading Condition}

The constructed slabs were divided into three categories with seven slabs in each category.First category of slabs were simply supported and subjected to two point static loading. A clear span of $2200 \mathrm{~mm}$ was adopted between the supports. The load was applied using a 50 tones capacity hydraulic jack and 50 tones proving ring and distributed at two points on the slab. The load was given in increments of $2 \mathrm{KN}$ at each stage of loading. The slabs were kept on the loading frame and were instrumented with a linear variable differential transformer (LVDT range $0-100 \mathrm{~mm}$ ) at mid span to monitor deflection. LVDTs of range $0-75 \mathrm{~mm}$ were used to monitor deflections at right and left loading points of the slab. Demec gauge (Demouldable mechanical gauge) pellets were pasted at the topmost compression fibre axis, at the middle axis and at the level of reinforcements of slab to note down the strains. Crack widths were measured using crack detection microscope. The experimental setup of static loading is shown in Fig. (1). The results of static test of slabs

Table 2. Properties of Reinforcements

\begin{tabular}{|c|c|c|c|c|c|}
\hline S1.No & Specification of Reinforcements & $\boldsymbol{f}$ (Mpa) & $\boldsymbol{E},(\mathbf{G p a})$ & $\boldsymbol{d}_{f}, \mathbf{m m}$ & \multicolumn{1}{c|}{ Strain, $\boldsymbol{\varepsilon}_{f}$} \\
\hline \hline 1 & G1 & 550 & 45 & 10 & 0.012 \\
\hline 2 & G2 & 690 & 88 & 10 & 10 \\
\hline 3 & S & 415 & 200 & 0.0078 \\
\hline
\end{tabular}

$G 1 \equiv$ Grooved GFRP reinforcements; G2 $\equiv$ Sand Coated GFRP reinforcements ; $f \equiv$ Tensile strength of reinforcements; $E \equiv$ modulus of elasticity of reinforcements; $d_{f}$, $\equiv$ diameter of reinforcements; $\varepsilon_{f} \equiv$ Strain of reinforcements at ultimate load $=f / E$ 
are presented in Table 3. The designations of the various parametric slabs are well explained below the Table 3 .

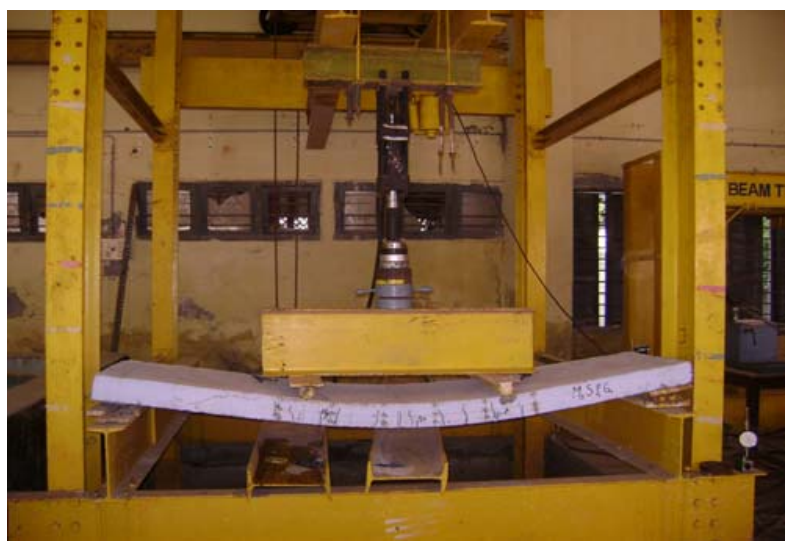

Fig. (1). Experimental setup for testing the slabs.

Second category of slabs were subjected to constant amplitude of fatigue loading scheme. By applying constant amplitude loading scheme, the slabs were subjected to sinusoidal wave form fatigue load cycles between a minimum load level and a maximum load level. Fig. (2) shows the pattern of fatigue loading applied on the slabs. Prior to start the fatigue loading, the slabs were precracked by applying smaller magnitude of static loading to observe the first crack load and initial propagation of the cracks. After that the minimum load level was set at $10 \%$ of ultimate static load of $M_{2} G_{1} \rho_{1} D_{1} \quad\left(\mathrm{M}_{2}\right.$ refers to grade of concrete, $20 \mathrm{~N} / \mathrm{mm}^{2}$; $\mathrm{G}_{1}$ refers to grooved type GFRP reinforcement; $\rho_{1}$ refers to the reinforcement ratio $0.65 \%$; and $\mathrm{D}_{1}$ refers to the thickness of the slab $100 \mathrm{~mm}$ ) slab to prevent any impact effect due to repeated loading and also to represent the effect of superimposed loads on a bridge like pavement. The maximum load level was set at $80 \%$ of ultimate static load of $M_{2} G_{1} \rho_{1} D_{1}$ reinforced slab and applied uniformly at a rate of $4 \mathrm{~Hz}$ till the failure of the slab. This procedure was followed up for all the slabs. The fatigue loading range was chosen to be approximately symmetrical around the service load. Therefore the upper limit simulates some kind of overloading on the specimen to enable the failure of the slab within a reasonable time [10]. All slabs were tested under two point loading with simply supported conditions. A $20 \mathrm{~mm}$ thick neoprene sheet was used between the steel plate and the concrete surface to avoid stress concentration. A $50 \mathrm{KN}$ capacity with $250 \mathrm{~mm}$ stroke cyclic load tester controlled by computer was programmed to apply the repeated loading on the slab. A deflectometer was used to examine the residual deflection at mid point of slab specimen after every 1000 number of cycles. The results of slabs under constant amplitude of fatigue loading are presented in Table 4. Fig. (3). shows the experimental test set up for repeated fatigue loading. Fig. (4) is the Bar

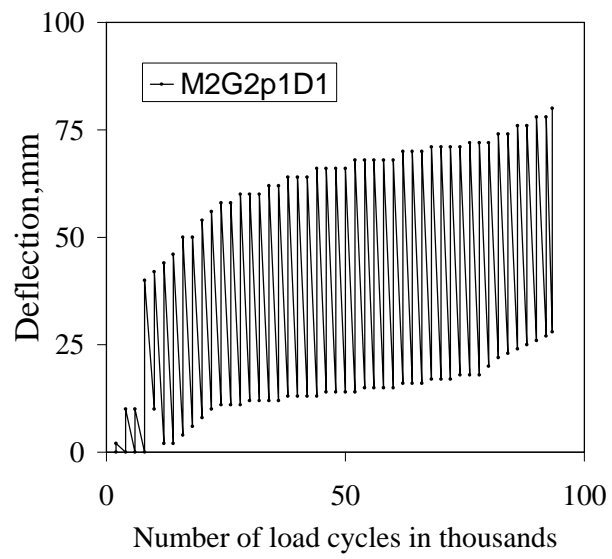

Fig. (2). Sinusoidal wave form of constant amplitude fatigue loading applied on the slab reinforced with sand coated GFRP reinforcements.

Table 3. Experimental and Theoretical Results of Slab Specimens (Static Loading Condition)

\begin{tabular}{|c|c|c|c|c|c|c|c|c|}
\hline SL NO & Specification of the Slab Specimens & $P_{c r}$ & $P_{u}$ & $P_{c r}$ & $P_{u}$ & $\delta_{\text {theo }}$ & $\delta_{\exp }$ & $w_{c r}($ mono $)$ \\
\hline 1 & $M_{2} G_{1} \rho_{1} D_{1}$ & 11.4 & 33 & 11.5 & 40 & 67.8 & 70.2 & 1.2 \\
\hline 2 & $M_{2} G_{2} \rho_{1} D_{1}$ & 11.4 & 43.6 & 12 & 55.2 & 61 & 59.2 & 0.9 \\
\hline 4 & $M_{2} G_{2} \rho_{3} D_{1}$ & 12.0 & 56.2 & 12.6 & 65.4 & 62.2 & 52.4 & 0.7 \\
\hline 5 & $M_{3} G_{2} \rho_{1} D_{1}$ & 11.6 & 49.2 & 12.8 & 60.2 & 56.5 & 54.6 & 0.8 \\
\hline 6 & $M_{2} G_{2} \rho_{1} D_{2}$ & 19 & 62.5 & 22.6 & 73.5 & 40.2 & 45.6 & 0.42 \\
\hline 7 & $M_{2} S \rho_{1} D_{1}$ & 11 & 30.4 & 11.5 & 40 & 30.4 & 40.8 & 0.36 \\
\hline
\end{tabular}

$M_{2} M_{3} \equiv$ Grades of concrete $\mathrm{M}_{20}, \mathrm{M}_{30}$ respectively; $G_{1}, G_{2}, S \equiv$ Grooved, Sand coated GFRP and Steel reinforcements; $\rho_{l}, \rho_{2 \varkappa}, \rho_{3} \equiv$ Different reinforcement ratios $0.65 \%, 0.82 \%$ \& $1.15 \%$ respectively; $\mathrm{D}_{1}$ and $\mathrm{D}_{2} \equiv$ Thickness of slabs

For example, Designation of the slab:

$M_{2} G_{1} \rho_{1} D_{1} \Rightarrow M_{2} \equiv$ grade of concrete $M_{20} ; G_{1} \equiv$ Grooved type GFRP reinforcement $\rho_{1} \equiv$ Reinforcement ratio,0.65\%; $D_{1} \equiv$ thickness of slab,100 mm. 
Table 4. Fatigue Test Results of the Slabs (Constant Amplitude Repeated Loading)

\begin{tabular}{|c|c|c|c|c|c|}
\hline Sl no & Designation of Slabs & Number of Load Cycles & $w_{c r(f a t i)} \mathbf{m m}$ & Residual Deflection, mm & $\mathbf{P}_{2} / \mathbf{P}_{1}$ \\
\hline 1 & $M_{2} G_{1} \rho_{1} D_{1}$ & 65,120 & 1.8 & 52 & 0.8 \\
\hline 3 & $M_{2} G_{2} \rho_{2} D_{1}$ & $1,50,000$ & 1.0 & 40 & 0.55 \\
\hline 4 & $M_{2} G_{2} \rho_{3} D_{1}$ & $3,02,210$ & 0.74 & 36 & 0.49 \\
\hline 6 & $M_{2} G_{2} \rho_{1} D_{2}$ & $4,00,000$ & 0.5 & 20.6 & 0.44 \\
\hline 7 & $M_{2} S \rho_{1} D_{1}$ & 67,510 & 0.4 & 35.2 & 0.8 \\
\hline
\end{tabular}

$\mathrm{P}_{1}=$ Ultimate static load of $M_{2} G_{1} \rho_{1} D_{1} \mathrm{P}_{2}=$ Ultimate static load of all the slabs.

chart showing the number of load cycles applied on the various types of slabs till failure of the slabs.

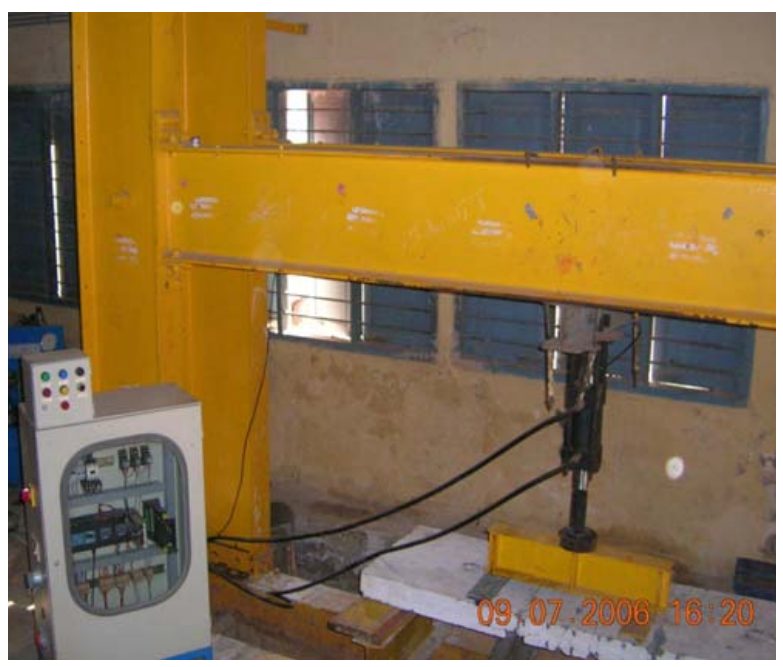

Fig. ( 3). Experimental setup for fatigue loading.

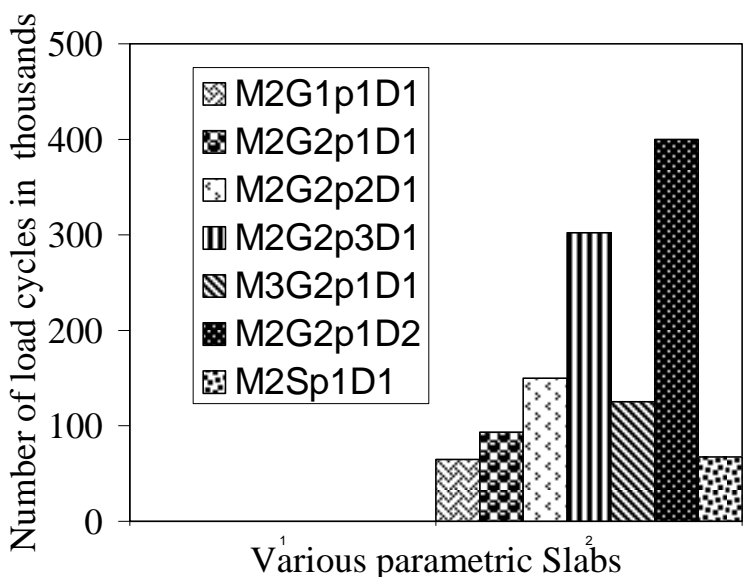

Fig. (4). Bar chart showing the number of load cycles applied on the various types of slabs till failure of the slabs.
Third category of slabs were subjected to variable amplitude of fatigue loading scheme by selecting $2 \mathrm{KN}$ as minimum load for all the slabs and different percentages like $20 \%, 40 \%, 60 \%$, and $80 \%$ of the static ultimate loads of the slabs were selected as maximum loads to access the effect of cycling at lower peak load levels. Each fatigue loading step consisted of minimum load of $2 \mathrm{KN}$ to a specified percentage of ultimate load. Each and every fatigue loading steps was applied for 10,000 cycles at a frequency of $4 \mathrm{~Hz}$ till failure of the slab occurs. The degree of fatigue damage can be evaluated by the magnitudes of strains in reinforcement, crack width, elastic deflection and residual (plastic) deflection. The magnitude of residual deflections is the energy dissipation of the slab which is considered as a proper measure to estimate the degree of damage. The deflections, crack widths, crack propagation, crack patterns, modes of failure and number of cycles up to failure were measured during the repeated loading at the end of each repeated loading step. The results of slabs under variable amplitude of fatigue loading are presented in Tables. 5 and $\mathbf{6}$.

\section{MATHEMATICAL MODELLING}

\section{Analytical Derivation of Moment Curvature Relation}

Some fairly reliable predictions in the design of FRP reinforced concrete members for flexure have been obtained and presented in this paper according to IS codal provisions. As suggested by Ganesh Thiagarajan [11], the design of FRP reinforced concrete members for flexure is similar to that of steel reinforced member. The moment curvature relationship (theoretical) is based on continuity of displacement across the depth, existence of perfect bond between GFRP reinforcements and concrete and the stress- strain relationship for the two materials.

Moment capacity and curvature strain $\varepsilon_{f}$ in reinforcement at the ultimate limit state can be calculated as

$$
\varepsilon_{f}=\frac{C_{E} f_{f}}{E_{f}}
$$

The limiting depth of neutral axis corresponds to the balanced section is expressed as 
Table 5. Crack Widths at Different Load Levels (Variable Amplitude Repeated Loading)

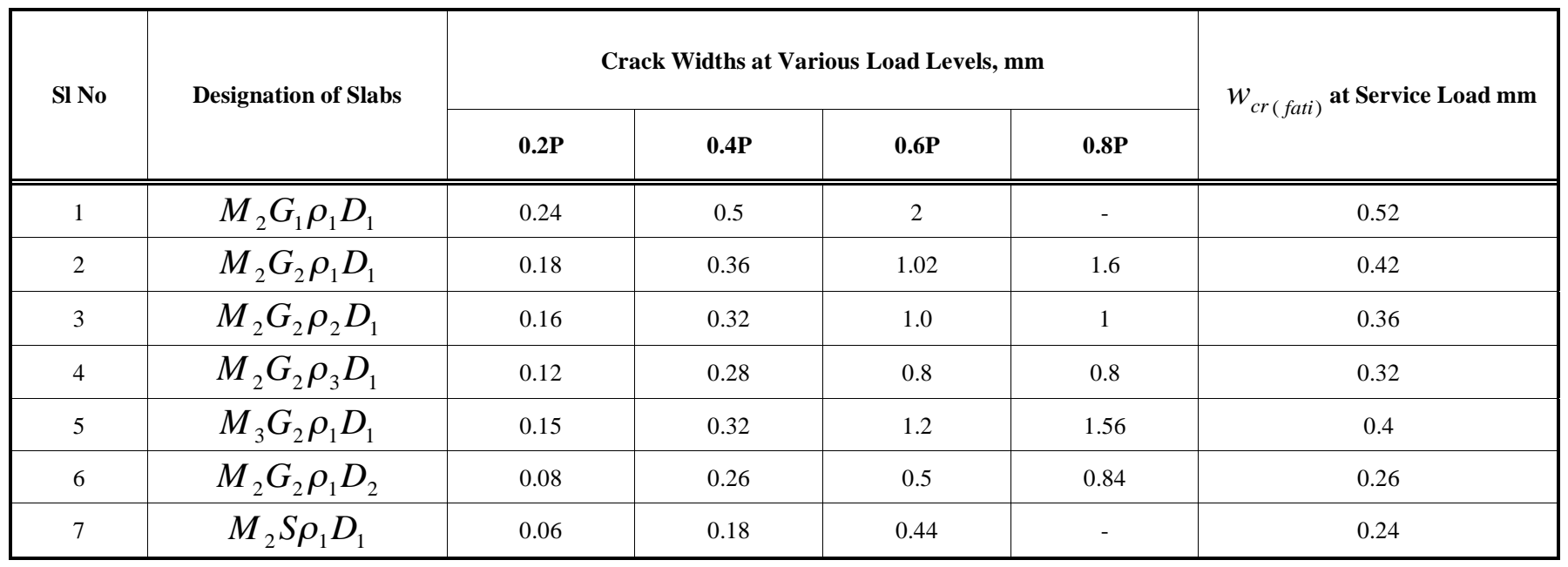

$\mathrm{P}=$ Static Ultimate load of the corresponding slabs.

Table 6. Deflections at Different Load Levels (Variable Amplitude Repeated Loading)

\begin{tabular}{|c|c|c|c|c|c|}
\hline SI No & Designation of Slabs & $0.2 P$ & $0.4 \mathrm{P}$ & $0.6 P$ & $0.8 \mathrm{P}$ \\
\hline 1 & $M_{2} G_{1} \rho_{1} D_{1}$ & 15.2 & 41.2 & 75.6 & - \\
\hline 2 & $M_{2} G_{2} \rho_{1} D_{1}$ & 11.2 & 34.2 & 54.2 & 66.5 \\
\hline 4 & $M_{2} G_{2} \rho_{3} D_{1}$ & 9.5 & 30.8 & 50.3 & 63.6 \\
\hline 5 & $M_{3} G_{2} \rho_{1} D_{1}$ & 10.5 & 32.4 & 52.6 & 62.4 \\
\hline 6 & $M_{2} G_{2} \rho_{1} D_{2}$ & 5.2 & 20.3 & 29.2 & 46 \\
\hline 7 & $M_{2} S \rho_{1} D_{1}$ & 10.4 & 26 & 45.8 & - \\
\hline
\end{tabular}

$$
\frac{x_{u \max }}{d}=\frac{\varepsilon_{\mathrm{c} u}}{\varepsilon_{\mathrm{c} u}+\varepsilon_{f}}=\frac{\varepsilon_{\mathrm{c} u}}{\varepsilon_{c u}+\left(C_{E} f_{f} / E_{f}\right)}
$$

If the neutral axis depth $x_{u}$ is less than $x_{u \max }$, then the section is under reinforced. If $x_{u}$ exceeds $x_{u \text { max }}$, it is over reinforced (in case of steel).But in GFRP, the failure results always in concrete crushing which is followed by rupture of FRP bars.

For a rectangular section of width $b$, the ultimate compressive force

$$
\begin{aligned}
& C_{u}=0.67 f_{c k} \mathrm{~b}\left[\frac{3 x_{\mathrm{u}}}{7}+\left(\frac{2}{3} \times \frac{4 x_{\mathrm{u}}}{7}\right)\right] \\
& =0.54 f_{c k} b x_{u}=\alpha f_{c k} b x_{u} \text { taking } \alpha=0.54
\end{aligned}
$$

Accordingly, considering moments of compressive forces about maximum compressive strain location $\bar{x}=0.28 x_{u}$ keeping $\beta_{1}=0.28$

For any given section, to satisfy equilibrium of forces, the depth of neutral axis should be such that $C_{u}=T_{u}$ Equating $C_{u}=T_{u}$ with expressions for $C_{u}$ and $T_{u}$ the expression for $x_{u}$ can be obtained as given below

$$
\alpha f_{c k} b x_{u}=C_{E} f_{f} A_{f}
$$

(where $C_{E}$ is the environmental reduction factor $=0.7$ for GFRP when concrete is exposed to ground and weather)

$x_{u}=\frac{C_{E} f_{f} A_{f}}{\alpha f_{c k} b}$

The location of the total compressive force in concrete can be expressed in terms of two factors $\alpha\left(\varepsilon_{c}\right)$ and $\gamma_{c}\left(\varepsilon_{c}\right)$ which are computed as Eqns (7) and (8). The moment curvature relationships are generated for different 
extreme concrete fiber strain values $\varepsilon_{c}$ starting from 0 to 0.0035 . For each value of $\varepsilon_{c}$, the location of the neutral axis $x_{u}$ is determined from the axial force equilibrium equation which can be expressed as Eqn. (9).

$$
\begin{aligned}
& \alpha\left(\varepsilon_{c}\right)=\frac{\int_{0}^{\varepsilon_{c}} f_{c}\left(e_{c}\right) d e_{c}}{f_{c} \varepsilon_{c}} \\
& \gamma\left(\varepsilon_{c}\right)=\left[1-\frac{\int_{0}^{\varepsilon_{c}} e_{c} f_{c}\left(e_{c}\right) d e_{c}}{e_{c}} \int_{0}^{\varepsilon_{c}} f_{c}\left(e_{c}\right) d e_{c}\right. \\
& P\left(\varepsilon_{c}, k\right)=\alpha\left(\varepsilon_{c}\right) \cdot f_{c k} \cdot b \cdot \beta_{1} x_{u}+f_{f}\left(\varepsilon_{f}, \beta_{1}\right) A_{f} \\
& \text { Where } f_{f}=E_{f} \cdot \varepsilon_{f} \text { is the stress in the GFRP reinfor- } \\
& \text { cement.. The neutral axis is determined by finding the value } \\
& \text { of } \beta_{1} \text { for which the above equation is zero. The moment for } \\
& \text { the above concrete strain value is then computed from the } \\
& \text { following expressions } \\
& M_{\text {concrete }}\left(\varepsilon_{c}\right)=\alpha\left(\varepsilon_{c}\right) f_{c k} b \cdot k d\left(k d-\gamma\left(\varepsilon_{c}\right) k d\right) \\
& M_{\text {tension }}=C_{E} f_{f} A_{f}\left(d-\beta_{1} x_{u}\right)
\end{aligned}
$$

Where $d=$ distance of the tension reinforcements from the bottom of the cross section. is given

In the case of singly reinforced section the lever arm is

$z=d-\beta_{1} x_{u}$

Accordingly, in terms of concrete compressive strength

$$
M_{u}=\alpha f_{c k} b x_{u} z
$$

In terms of tensile reinforcements

$M_{u}=C_{E} f_{f} A_{f} z$

The limiting percentage of FRP is given by

$$
\rho_{f b}=\alpha\left(\frac{f_{c k}}{C_{E} f_{f u}}\right)\left(\frac{x_{u \max }}{d}\right) 100
$$

Where $\rho_{f b}=\left(\frac{A_{f b}}{b d}\right)$ in which $A_{f b}$ is the area of GFRP reinforcement for the balanced section and $b, d$ are the width and effective depth of the cross section respectively. $f_{c k}$ is the cube compressive strength of concrete $f_{f u}$ is the rupture stress (the sudden, complete failure of a plastic specimen held under a constant load ) of the FRP reinforcement. $E_{f}$ is the modulus of elasticity of the FRP reinforcement. The design philosophy of limit state method describes two distinct factors such as ultimate limit states (dealing with the strength) and serviceability limit states (dealing with the cracking, deformability and ductility). According to elastic bending theory, the deflection can be expressed as

$$
\delta_{s \max }=\frac{M_{a}}{24 E_{c} I}\left(3 L^{2}-4 a^{2}\right)
$$

Neglecting the shear component of deflection, the following expression fairly predicts the ultimate deflection

$\delta_{\max }=k_{m} \phi_{\max } l^{2}$

Where $k_{m}=23 / 216=\mathrm{a}$ constant factor that depends on the type of loading and support conditions; $l=$ length of the clear span; $\phi_{\max }=\frac{\varepsilon_{c u}+\varepsilon_{f_{u}}}{d}=$ curvature at ultimate

The crack width can be measured by the well known Gergely-Lutz formula

$$
w_{c r}=k_{g} f_{f} \frac{h_{2}}{h_{1}} k_{b} \sqrt[3]{d_{c} A}
$$

Where $k_{g}=\frac{2.2}{E_{f}}$ is a coefficient varying according to the material; $f_{f}=$ stress at the centroid of the rebar in tension $; \quad h_{2}=D-k d ; h_{1}=d-k d ; d_{c}=$ thickness of concrete cover measured from the extreme tension fibre to the centre of the nearest bar; $d=$ depth of neutral axis; $D=$ overall depth of the member;

$A=\frac{A_{e}}{n}=\frac{2(D-d) b}{n} ; n=$ number of bars in tension; $b=$ breadth of the slab

\section{RESULTS AND DISCUSSION}

\section{Discussion of Test Results}

The results of static load tests are shown by Fig. $(\mathbf{3 , 4})$ and (5). Under static loading condition the ultimate load carrying capacity of $M_{2} G_{2} \rho_{1} D_{1}$ slab was $40 \%$ greater as compared to $M_{2} G_{1} \rho_{1} D_{1}$ and $M_{2} S \rho_{1} D_{1}$ slabs. The ultimate deflection of $M_{2} G_{2} \rho_{1} D_{1}$ was observed as 0.75 times smaller than $M_{2} G_{1} \rho_{1} D_{1}$ and 2.5 times greater than $M_{2} S \rho_{1} D_{1}$.Lesser amount of deflections and smaller crack widths were observed in sand coated GFRP slabs than the grooved GFRP slabs. This might be attributed by the good bonding effect existing between the reinforcements and concrete .By increasing the reinforcement ratio, grade of concrete and the thickness of the slabs, the maximum load carrying capacity of the slabs increases and the corresponding deflection decreases. When the reinforcement ratio of sand coated GFRP reinforced slabs was increased from 
$0.65 \%$ to $1.15 \%$, the ultimate load carrying capacity increases from $6 \%$ to $20 \%$ and rapid changes were not perceived in the corresponding deflections. The increase in the thickness of the sand coated GFRP slabs, improved the static load carrying capacity by $35 \%$, and lowered the corresponding deflection by 0.7 times. On increasing the grade of concrete from $20 \mathrm{~N} / \mathrm{mm}^{2}$ to $30 \mathrm{~N} / \mathrm{mm}^{2}$ for the sand coated GFRP reinforced slabs, $10 \%$ improvement in the ultimate load carrying capacity and an insignificant change in deflection (i.e., the stiffness of the slabs did not change much when the concrete strength increases by $\left.10 \mathrm{~N} / \mathrm{mm}^{2}\right)[12,13]$ were observed. The similar observation was noticed and presented by Theriault et al. 1998. The flexural response of various slabs are shown in Fig. 5, 6 and 7. The theoretical and experimental loaddeflection responses of slabs are presented in Fig. (8).

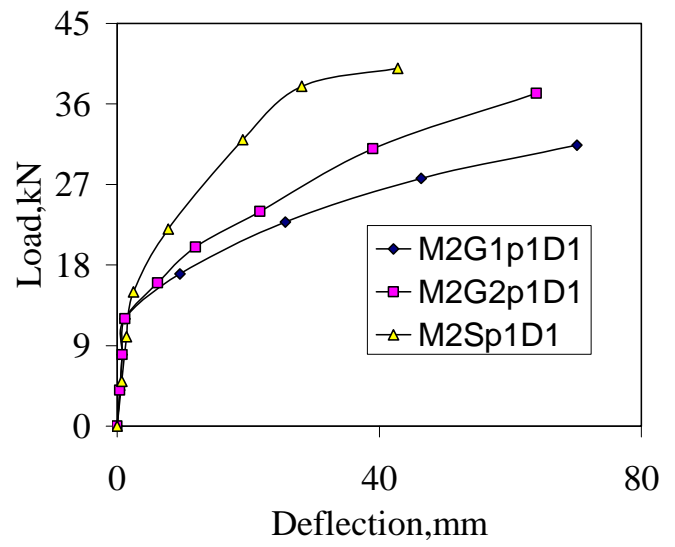

Fig. (5). Flexural response of one way slabs reinforced with different types of reinforcements.

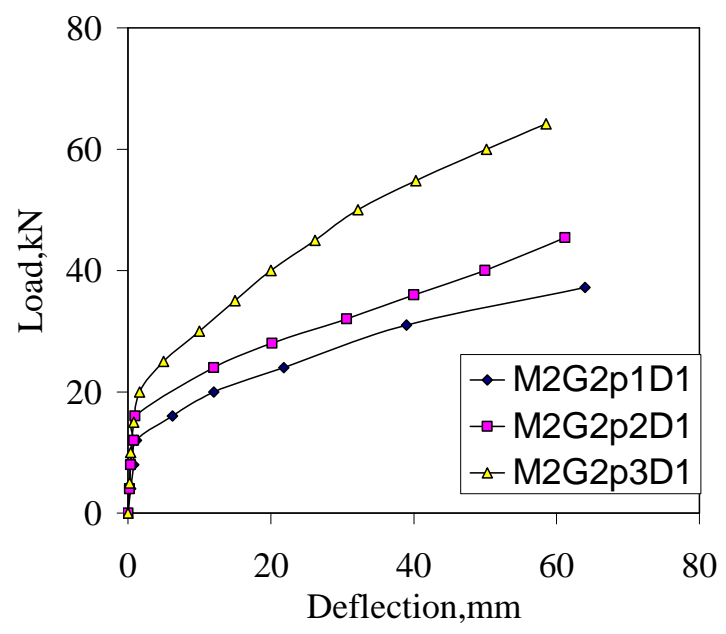

Fig. (6). Effect of varying the reinforcement ratios of one way slabs reinforced with Sand coated GFRP reinforcements on the Flexural response.

\section{Repeated Cyclic Loading Results}

Based on repeated cyclic loading results, it was observed that with the increase in the number of load cycles, the corresponding ultimate deflection, number of cracks and the width of the cracks increase. The slab $M_{2} G_{2} \rho_{1} D_{1}$ showed 1.43 times and 1.38 times greater fatigue performance than $M_{2} G_{1} \rho_{1} D_{1}$ and $M_{2} S \rho_{1} D_{1}$ slabs respectively. The fatigue performance of $M_{2} G_{2} \rho_{1} D_{2}$ slab was observed as 4.3 times higher than $M_{2} G_{2} \rho_{1} D_{1}$ slab. Also, by increasing the grade of concrete from $20 \mathrm{~N} / \mathrm{mm}^{2}$ to $30 \mathrm{~N} / \mathrm{mm}^{2}$, the fatigue performance of $M_{2} G_{2} \rho_{1} D_{1}$ was increased by 1.34 times. The fatigue capacity of $M_{2} G_{2} \rho_{1} D_{1}$ exceeded the fatigue capacities of $M_{2} G_{2} \rho_{2} D_{1}$ and $M_{2} G_{2} \rho_{3} D_{1}$ by 1.6 and 3.24 times respectively. It was also noted that the magnitude of damage accumulated to the slab reinforced with steel reinforcements is higher than GFRP reinforced slabs. Among all the GFRP reinforced slabs, sand blasted GFRP reinforced slabs exhibited the lowest residual deflection and the greatest stiffness. Sand blasted GFRP reinforced slabs proved an excellent fatigue performance over the slabs reinforced with other types of reinforcements. It has been observed that at the same load level, the deflection under cyclic loading is always greater than the deflection under static loading. On increasing the number of load cycles, the stiffness of the slab decreases and the increasing residual and elastic deflections confers the peak load level. Fig. (9) shows the S-N curve drawn on the basis of the fatigue test values of constant amplitude.

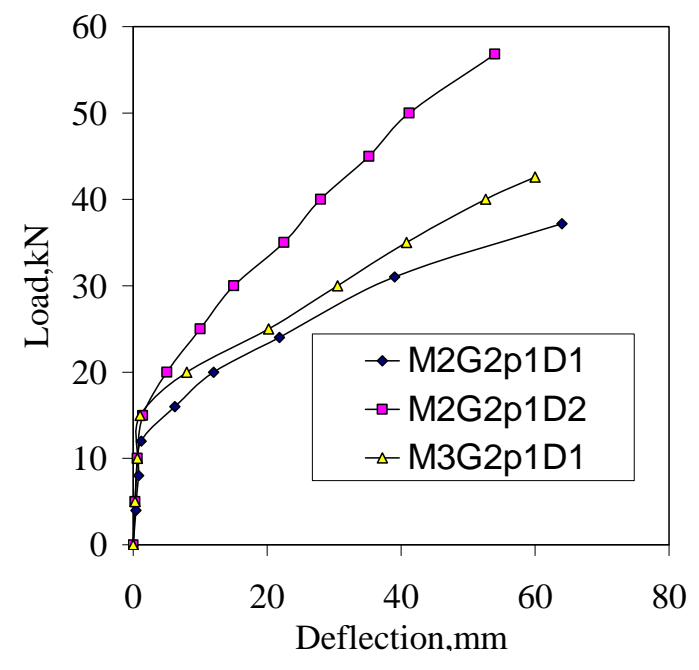

Fig. (7). Effect of varying the depth and the grade of concrete of one way slabs reinforced with Sand coated GFRP reinforcements on the Flexural response.

\section{Fatigue Life Modeling of GFRP Reinforced One-Way Slabs}

The results of fatigue test for the investigation of flexural behaviour of GFRP reinforced slabs and Steel reinforced slabs were shown in Table 4,5 and $\mathbf{6}$.

The first approach developed due to fatigue assessment was represented by $\mathrm{S}-\mathrm{N}$ curves which are also known as Wohler Curves. $S$ is the fatigue strength (which is the percentage ratio of static ultimate loading $\mathrm{P}_{1}$ of $M_{2} G_{1} \rho_{1} D_{1}$ to 


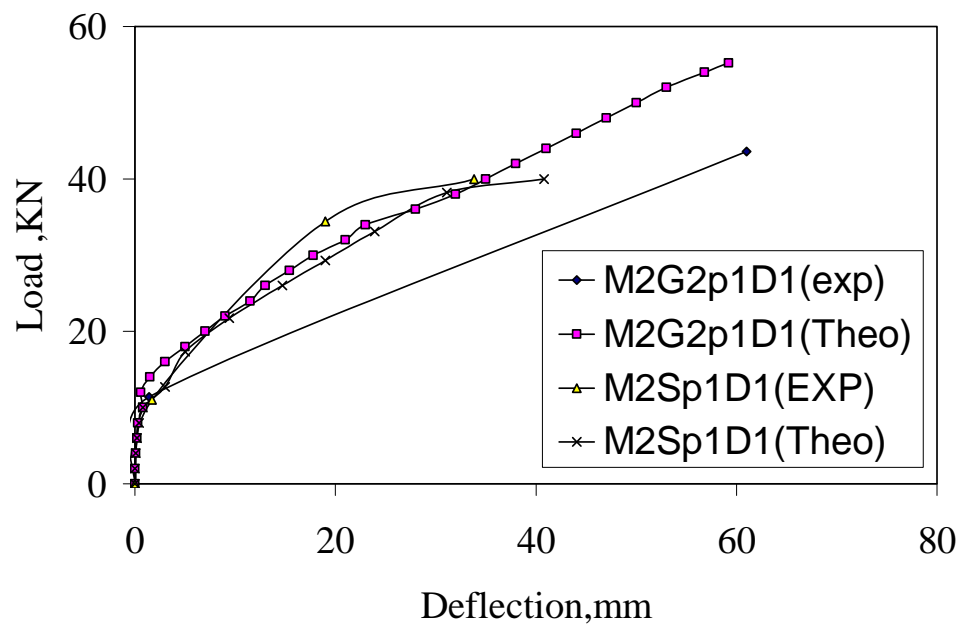

Fig. (8). Comparison of experimental and theoretical values of slabs reinforced with sand coate GFRP reinforcements and conventional reinforcements.

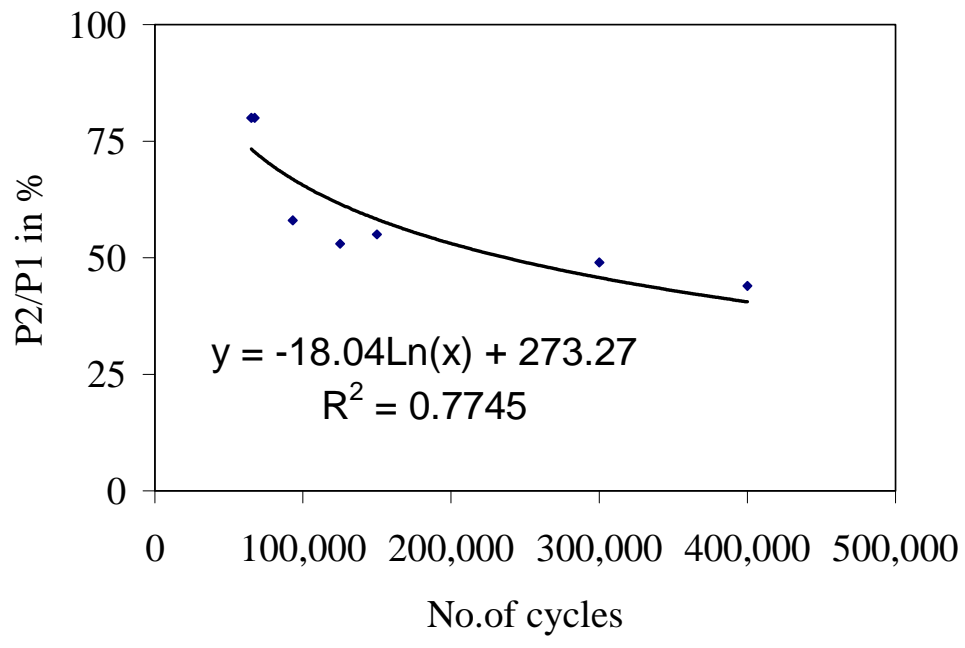

Fig. (9). S-N curve (A Regression Analysis).

static ultimate loading $\mathrm{P}_{2}$ of the corresponding slabs )and $N$ is the fatigue life of slabs in terms of number of load cycles. These curves can be drawn only for constant amplitude loading stress histories (Table 4). The general form of equation regarding the relation between the operational stresses applied and the number of cycles is shown as

$Y=B * \operatorname{Ln} N+A$

where A and B are experimental constants decided from the test values.

The regression analysis and interpretation of the experimental test results in this study yields the following equation.

$S=-18.04 \operatorname{Ln}\left(N_{f}\right)+273.27$

where $\left(R^{2}=0.7745\right)$

\section{Crack Growths and Modes of Failure}

Cracks appeared at the bottom surfaces of concrete slabs whenever the tensile stresses exceeded the modulus of rupture of concrete. The first crack appeared at the middle of the slab and developed slowly across the width of the slab (i.e. parallel to the supports). The second crack formed at the right loading line of the slab and subsequently at the left loading line of the slab. Further development of flexural cracks occurred parallel to these cracks and slowly propagated throughout the thickness of the slab, on increasing the application of load under static loading and on increasing the number of load cycles under the fatigue loading. At ultimate load, GFRP reinforced slabs failed by crushing of concrete followed by the rupture of GFRP reinforcements whereas the Steel reinforced slabs failed by the yielding of steel which was then followed by crushing of concrete [14, 15]. GFRP reinforced concrete slabs experienced better performance 
and longer fatigue life as compared with the slabs reinforced with steel. This might be due to the closer values of modulii of elasticity of GFRP reinforcements and concrete in addition to their linear-elastic behaviour. From the experimental results it was observed that sand blasted GFRP reinforced slabs showed the better fatigue performance than the other slabs. Fig. (10) shows the development of crack width while applying the static load gradually for the slabs constructed with varying parameters. The crack patterns of slabs reinforced with different types of reinforcement are depicted in the Fig. (11-13). The failure of a typical GFRP reinforced slab is shown in Fig. (14).

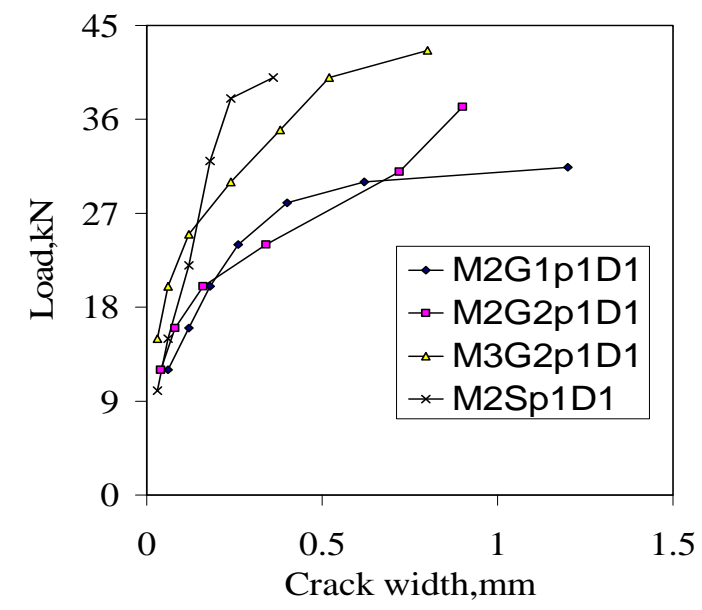

Fig. (10). Graph showing the development of crack width while applying the static load gradually for the slabs constructed with varying parameters.

\section{CONCLUSIONS}

Experiments carried out on twenty one number of oneway concrete slabs, (out of which three are reinforced with conventional steel reinforcements and eighteen are reinforced with GFRP reinforcements) were studied. A rigorous analytical and experimental studies on the behaviour of conventional and GFRP reinforced concrete one way slab under static and repeated loading were investigated by considering reinforcement ratios, grade of concrete, thickness of slab and type of GFRP reinforcements (with constant and variable amplitude loadings). All the slabs experienced flexural type of failure. At ultimate load, GFRP reinforced slabs experienced concrete crushing followed by the rupture of GFRP reinforcements. On increasing the thickness, grade of concrete, reinforcement ratio of the slabs, the ultimate load carrying capacities of GFRP reinforced slabs were increased and the corresponding strains in terms of deflection and crack width were reduced. GFRP reinforced concrete slabs experienced better performance and longer fatigue life when compared to the conventional slabs. This was mainly attributed due to the closer values of the modulii of elasticity for GFRP reinforcements and concrete in addition to the linear-elastic behaviour of GFRP reinforcements. Sand coated GFRP reinforcements showed the better fatigue performance than the grooved GFRP reinforcements due to their higher bonding characteristics. From the experiments, it was perceived that at service load level, the developed crack width satisfied the formulated recommendations. Due to the low modulus of elasticity and different bond characteristics of the GFRP reinforcements, slabs reinforced with GFRP reinforcements exhibited larger deflections and strains than those reinforced with conventional steel reinforcements. Sand coated reinforced GFRP slabs experienced 1.6 times greater fatigue life than

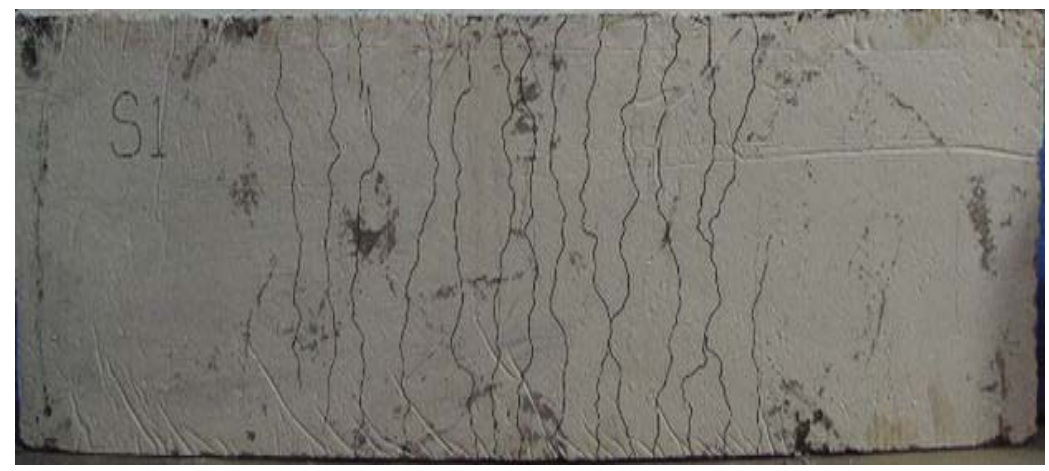

Fig. (11). Crack pattern of conventional slab.

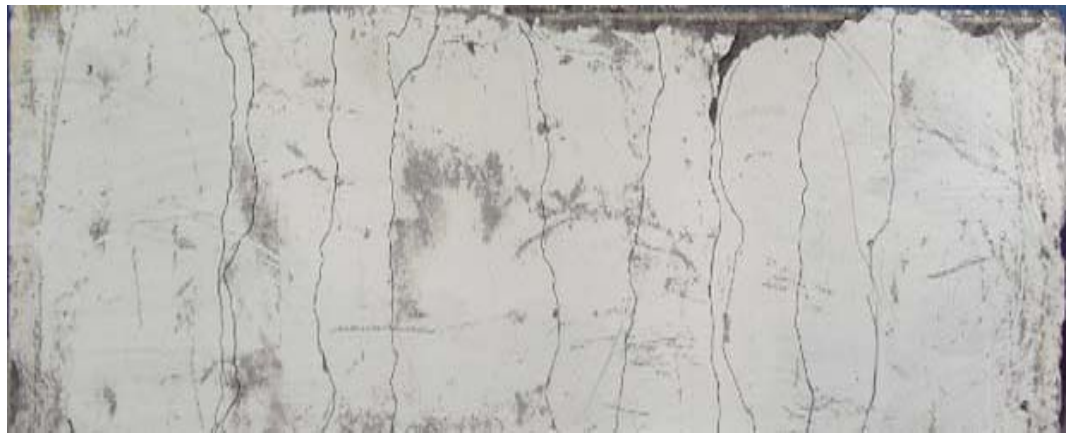

Fig. (12). Crack pattern of GFRP 1 reinforced slab. 


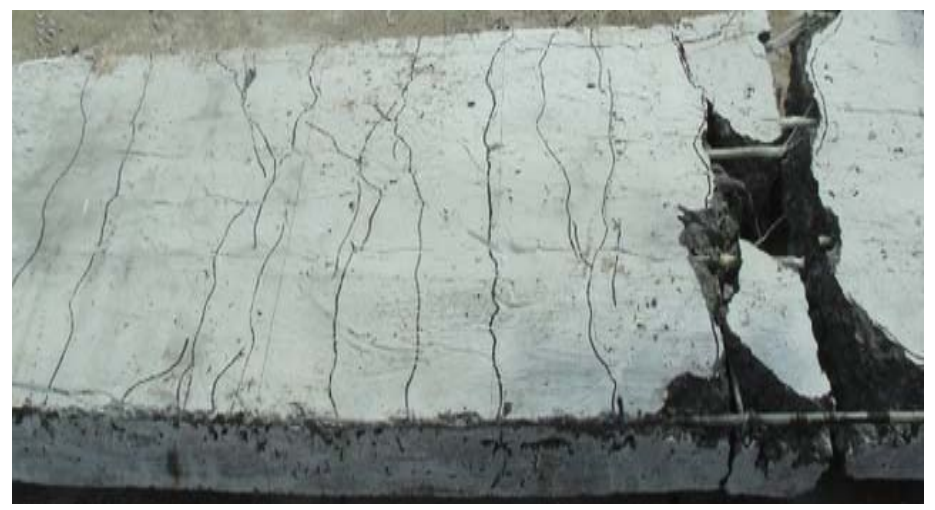

Fig. (13). Crack pattern of GFRP 2 reinforced slab.

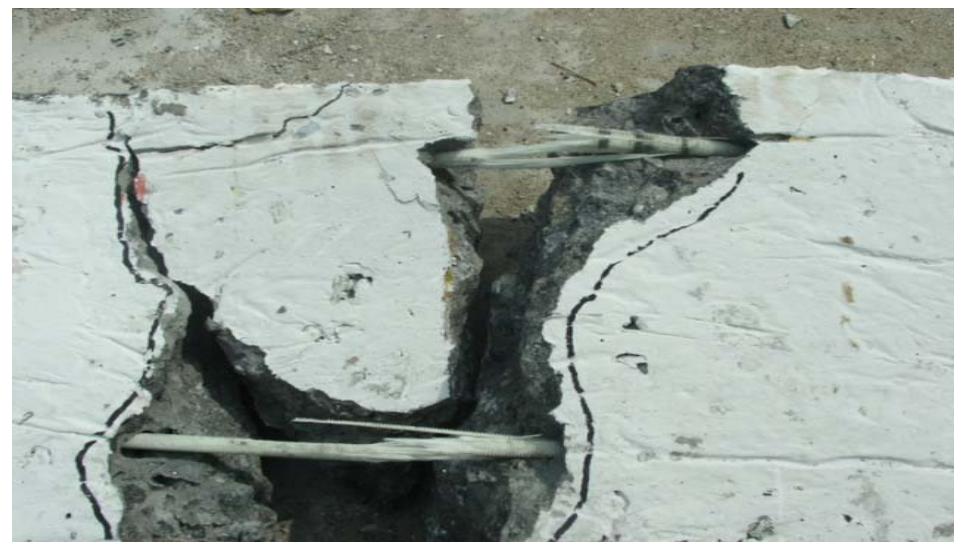

Fig. (14). Failure of GFRP slabs: Concrete crushing followed by the rupture of GFRP reinforcements.

greater fatigue life than that of conventional slabs. The fatigue performance of Grooved GFRP reinforced slabs is similar to that of conventional slabs. Based on this study, it is found that a good agreement exists between the theoretical and experimental results.

\section{ACKNOWLEDGEMENT}

The authors wish to thank the University Grants Commission (UGC) of India for the valuable financial support rendered from the UGC Major Research Scheme. The financial Grants released for the project titled "Alternative Reinforcements for Concrete Application" is greatly appreciated.

\section{NOTATIONS}

The following symbols are used in this paper:

$\begin{array}{lll}\alpha\left(\varepsilon_{c}\right) & =\begin{array}{l}\text { Factor to represent the compressive force } \\ \text { in concrete }\end{array} \\ \beta_{1} & =\begin{array}{l}\text { Factor to define the stress block in com- } \\ \text { pression zone }\end{array} \\ f_{c k} & =\quad \text { Cube strength of concrete } \\ \rho_{f b} & =\quad \text { Balaced reinforcement ratio } \\ x_{u} & =\quad \text { Depth of neutral axis }\end{array}$

$\begin{array}{ll}x_{u \max }= & \begin{array}{l}\text { Limiting depth of neutral axis correspon- } \\ \text { ding to balanced section }\end{array} \\ f_{f u} & =\begin{array}{l}\text { Rupture stress or ultimate stress of FRP } \\ \text { reinforcements }\end{array} \\ f_{f} & =\text { Tensile strength of FRP reinforcements } \\ \varepsilon_{c} & =\text { Maximum strain in concrete } \\ \gamma\left(\varepsilon_{c}\right)= & \begin{array}{l}\text { Factor to represent the location of com- } \\ \text { pressive force in concrete }\end{array} \\ P\left(\varepsilon_{c}, k\right)= & \text { Compressive forces due to stresses } \\ C_{E}= & \text { Environmental reduction factor }\end{array}$

\section{REFERENCES}

[1] ACI Committee 440 R-96, State-of-the-Art Report on Fibre Reinforced Plastic (FRP) Reinforcement for Concrete Structures. 1996.

[2] CAN/CSA-S6-02, "Design and Construction of building components with Fibre Reinforced Polymers", Canadian Standards Association, Toronto, Ontario, Canada, 2002.

[3] J.L. Clarke, "Alternative Materials for the Reinforcement and Prestressing of Concrete", Special structures Dept, Sir William Halcrow and partners, Chapman \& Hall, London, 1993.

[4] Z. Achillides, "Bond behaviour of FRP bars to concrete," Proceedings of the Third International Symposium (FRPRCS-3), Sapporo 1997, Japan Concrete Institute, vol. 2, pp. 341-348, 1997. 
[5] L. Calado, C.A. Castiglioni, and M.R.Agatino, "Experimental and Numerical Evaluation of Bond Stress of Concrete Beams Reinforced by GFRP Bars," Research report, 1996.

[6] Kae-Hwan Kwak, and Jong-Gun Park, "Shear-fatigue behavior of high-strength reinforced concrete beams under repeated loading", Journal of Structural engineering and Mechanics, vol. 2, no.3, pp.301-314,2001.

[7] Amr El-Ragaby, Ehab El-Salkawy and Brahim Benmokrane, "Fatigue analysis of Concrete Bridge Deck Slabs reinforced with EGlass/Vinyl Ester FRP Reinforcing bars," Journal of composites for construction, vol. 11, no.3, pp.258-268, 2007.

[8] M.R. Adimi, A.H. Rahman and B. Benmokrane, "New method for testing fiber-reinforced polymer rods under fatigue," Journal of composites for construction, vol. 4, no.4, pp.206-213, 2000.

[9] Amnon Katz, "Bond to concrete of FRP Rebars after Cyclic loading," Journal of composites for construction, vol. 4, no. 3, pp.137144, Aug. 2000.

[10] Sobhy Masoud, Khaled Soudki, and Tim Topper, "CFRP strengthened and corroded RC beams under Monotonic and Fatigue Loads," Journal of composites for construction, vol. 5, no. 4, pp.228-235, Nov.2001.
[11] A.M. Ganesh Thiagrajan, "Experimental and Analytical behaviour of Carbon Fiber-Based Rods as Flexural Reinforcement," Journal of composites for construction,ASCE, vol. 7, no.1, pp.64 -72, Feb.2003.

[12] Michale Theriault and Brahim Benmokrane, "Effects of FRP reinforcement ratio and concrete strength on flexural behavior of concrete beams," Journal of composites for construction, vol. 2, no.1, pp.7-16, Feb.1998.

[13] L. Ombres, T. Alkhrdaji, and A. Nanni, "Flexural analysis of one way concrete slabs reinforced with GFRP rebars," International meeting on composite materials, PLAST 2000,Proceedings, Advancing with composites 2000,Italy,pp.243-250,May.2000.

[14] Craig R. Michaluk, Sami H. Rizkalla, Gamil Tadros, and Brahim Benmokrane "Flexural behavior of one-way concrete slabs reinforced by Fibre reinforced plastic reinforcements," ACI Structural Journals vol. 95, no.3, pp.353-364,1998.

[15] R. Sivagamasundari., and G. Kumaran, "A critical study on the suitability of glass Fibre reinforced polymer reinforcements for concrete one way slabs," in International Conference on Recent Developments in Structural Engineering, Manipal Institute of Technology, Manipal, India,pp.265,Aug. 2007. 